\title{
Dangers of thrombolysis
}

\section{The benefits of thrombolytic treatment for acute myocardial infarction outweigh the risks}

All treatment is dangerous; the more powerful the treatment the greater the danger. Even the humble aspirin tablet may provoke indigestion and gastrointestinal blood loss. These side effects are, however, mild and reversible and are far outweighed by the benefit from treatment with aspirin in patients with acute coronary disease. For thrombolytic agents the balance is more even. The benefit in patients with acute myocardial infarction has to be set against the risk of bleeding. Treatment with thrombolytic drugs such as streptokinase has become widespread since publication of the results of the major trials. But results from careful clinical trials may not necessarily be borne out in everyday practice in coronary care units in district hospitals. Reports of complications have started to trickle in. It is time to take stock of the risks of thrombolytic treatment.

Early fears about thrombolytic treatment in patients with myocardial infarction were based on studies in animals. Reperfusion of the myocardium after a period of coronary occlusion was found to be associated with the development of ventricular arrhythmias including fibrillation and with other more subtle myocardial abnormalities such as stunning, microvascular damage, cell necrosis, and haemorrhage. These have not been seen to any extent in clinical practice, perhaps because we cannot examine the hearts of our patients so closely or perhaps because experimental reperfusion is sudden whereas clinical reperfusion is gradual. But the other predictable consequence of thrombolysis - bleeding - is certainly a worry.

In this issue two groups describe the administration of streptokinase to six patients who were subsequently shown to have aortic dissection ( $\mathrm{p} 513$ and p 517). This misfortune was reported in the ASSET trial in which alteplase (recombinant tissue plasminogen activator) was used ${ }^{2}$; it has certainly been seen elsewhere in Britain and overseas, and it is not surprising because the differential diagnosis of the gravely ill patient with severe chest pain and an abnormal electrocardiogram is difficult. Moreover, the decision to administer thrombolytic treatment has to be taken within minutes, usually by a junior doctor (a house officer in three of the four patients from Oxford). Both reports come from specialist centres. The patients survived long enough to reach these centres, and three left hospital, all after surgery - an experience that would be usual in similar patients who had not had thrombolysis. The lethal nature of aortic dissection implies that other unreported patients in district hospitals with this condition have died. Whether thrombolytic treatment makes any difference to the outcome remains doubtful.

Getting the diagnosis wrong is tragic but probably unavoidable given the circumstances. Even when the diagnosis is right, however, unforeseen disasters may still occur. For example, Stafford and his colleagues reported on seven patients in whom thrombolysis was followed by severe embolic complications that were probably a result of disintegration of a pre-existing clot. ${ }^{3}$ Other physicians will have seen patients with intracranial haemorrhage after thrombolysis, although this complication is rare. It does not get reported in journals because it was so clearly documented in the original trials. The overall incidence of cerebrovascular events was below $1 \%$ in both the GISSI ${ }^{+}$and ISIS $2^{5}$ trials and similar in both treated and control groups. In ISIS 2 only seven of the 8490 patients treated with streptokinase had confirmed haemorrhagic strokes. Bleeding from other sitesfor example, the gastrointestinal tract - was also well documented and so again will not be reported. Major bleeding requiring transfusion was reported in 46 patients $(0.5 \%)$ in ISIS 2. Nor are accounts published of the spectacular bruises that result from the puncture of arteries and veins, though these are a familiar sight nowadays.

As experience with thrombolytic agents grows so does the list of complications. Sensitivity reactions to streptokinase are fairly common but usually mild; proteinuria has excited attention recently and may be another manifestation of sensitivity. ${ }^{6}$ The relative risks of the three main thrombolytic agents - streptokinase, alteplase, and anistreplase - are being examined in ISIS 3. It seems likely that the risk of major bleeding will be small and that there will be little difference among the three, though their efficacy and cost may well differ.

Should we change our attitude towards thrombolysis as its dangers become better appreciated? Overall early mortality in the control and treated groups respectively in the major trials were as follows: $13.0 \%$ and $10.7 \%$ in GISSI and $12.0 \%$ and $9 \cdot 2 \%$ in ISIS 2 (both used streptokinase), ${ }^{+5} 12 \cdot 2 \%$ and $6 \cdot 4 \%$ in AIMS (with anistreplase), ${ }^{7}$ and $9 \cdot 8 \%$ and $7 \cdot 2 \%$ in ASSET (with alteplase). ${ }^{2}$ Thus about three in every 100 patients with acute myocardial infarction will have their lives saved by thrombolytic treatment; maybe one will suffer a major complication. As judged by improvement in left ventricular function there may be other benefits (such as freedom from cardiac failure). ${ }^{8}$ Few other forms of treatment have been introduced under such careful scrutiny or have given such clear results. We owe a debt of gratitude to the trialists, and we may conclude that we should continue to administer thrombolytic treatment to all patients with acute myocardial infarction except those with the now well defined contraindications - any bleeding diathesis, recent surgery or stroke, severe hypertension, aortic dissection, and peptic ulceration. Two other caveats must be added: a second dose of streptokinase carries an increased risk of sensitivity reactions and may be less effective'; and the decision to treat should be taken by a registered medical practitioner. Cautious physicians will still wish to insist on seeing the changes in the electrocardiogram that are characteristic of infarction before administering thrombolytic drugs, but many (including all of us who are participating in ISIS 3) will not. It may well be that most benefit will be seen in those patients who have not yet had an infarct and so do not show any change in the electrocardiogram.

Speedy thrombolysis as recommended by the British Heart Foundation remains the treatment of choice for suspected myocardial infarction. ${ }^{10}$ Sadly, many patients still do not receive such treatment."

M C PETCH

Consultant Cardiologist,

Regional Cardiac Unit, Papworth Hospital,

Cambridge CB3 8RE 
1 Anonymous. Reperfusion iniury after thrombolytic therapy for acute myocardial infarction [Editorial]. Luncet 1989;ii:655-7.

2 Wilcox RG, Olsson CG. Skeene AM, van der Lippe (i, Jenson (i, Hampton JR. Trial of tissue plasminogen activator for mortality reduction in acute myocardial infarction. Anglo-Scandinavian sudy of early thrombolysis ASSET L Lncet 1988;ii:525-30.

3 Stafford PJ, Strachan CJI, Vincent R, Chamberlain DA. Multiple microemboli after disintegration of clot during thrombolysis for acute myocardial infarction. Br.Med 7 1989;299:1310-2.

4 Gruppo Italiano per lo Streptochinasi nell'Infarto Miocardico GISSI). Effectiveness of intravenous thrombolstic treatment in acute myocardial infarction. Lancet 1986;i:397-402.

5 ISIS-2 Second International Study of Infarct Survival Collaborative Group. Randomised trial of intravenous streptokinase, oral aspirin, both or neither among 17187 cases of acute mvocardial infarction (ISIS-2). Lancet 1988;ii:349-60.
6 Payne ST, Hosker HSR, Allen MB, Bradbury H, Page RL. Transient impairment of renalfunction after streptokinase therapy. Lanct 1989;ii: 1398

7 Anisoylated Plasminogen Streptokinase Activator Complex Intervention Mortality Trial Study Group. Effect of intravenous APSAC on mortality after acute myocardial infarction: preliminary report of a placebo-controlled clinical tral. Lancet 1988:1:545-9.

8 White HD, Norris RM, Brown MA, et al. Effect of intravenous streptokinase on left ventricula function and early survival after acute myocardial infarction. $N \mathrm{Engl} / \mathrm{F}$.Med 1987;317:850-5. Jalihal S, Morris GK. Antistreptokinase titres after intravenous streptokinase. Lancet 1990;355: $184-5$

0 British Heart Foundation Working Group. Role of the general practitioner in managing patients with mvocardial infarction: impact of thrombolvtic treatment. Br Med f 1989;299:555-7. Burrell CJ Skehan VD, Cowley $\mathrm{ML}$, Barrett $\mathrm{CH}$, Mills PG. Districts' use of thrombolytic agents. Br Med f 1990;300:237-8

\title{
Multiple endocrine neoplasia type 2
}

\author{
The search for the gene continues
}

Multiple endocrine neoplasia type 2 (MEN 2) is one of the dominantly inherited cancer syndromes. In the most usual form, MEN 2A, tumours of the thyroid C cells (medullary thyroid carcinoma) are found with tumours of the adrenal medulla (phaeochromocytoma) and, in some people, parathyroid hyperplasia or adenoma.'

The gene for MEN 2A was mapped to chromosome 10 by genetic linkage in $1987 . .^{23}$ Progress since that time was reviewed at the third international workshop on MEN 2 in Heidelberg in 1989. Study worldwide of some 50 families with MEN 2A has found none in which the results are inconsistent with predisposition at the locus on chromosome 10. Even so, the possibility of heterogeneity cannot be excluded. Apart from MEN 2A two variants of MEN 2 are recognised that breed true in families: MEN 2B, in which additional phenotypic abnormalities are associated with an earlier onset of tumours and generally more aggressive behaviour of medullary thyroid carcinoma; and rare "MTC only" families in which medullary thyroid carcinoma is the only tumour, the onset is late, and the tumours are rarely if ever fatal. ' Recent data, updated at Heidelberg, suggest strongly that families with MEN 2B and perhaps those with medullary thyroid carcinoma only also have mutations at the same locus on chromosome $10 .^{+5}$ If so, once the gene(s) is cloned and sequenced comparison of the mutations that give rise to these different disease phenotypes is likely to be of considerable interest.

Before this stage can be reached the MEN 2 locus must be mapped more precisely. The MEN 2A gene has been localised to a small region defined by two sets of genetic markers, one set just above the centromere (the fibronectin $\beta$ chain ${ }^{6}$ and an anonymous DNA segment recognised by the probe TB14.34) and one set below the centromere (the interstitial retinol binding protein and the DNA segment recognised by the probe $\mathrm{MCK} 2^{7}$ ). Further progress with genetic mapping is, however, proving difficult. It depends on recombination between markers, and the region of the centromere, where the MEN 2 locus lies, is characterised by lack of recombination. This problem has directed attention to the parallel strategy of building a physical map defined by overlapping stretches of DNA identified by pulsed field gel electrophoresis. Such maps are oriented by reference to fixed points provided by a series of cell lines that can be prepared carrying different chromosome breaks that lie in the region of interest.

Even an excellent physical map, however, begs the question of how the MEN 2 gene will be recognised. One hope is that the mutation that causes MEN 2 will prove to be one that causes loss of activity of the gene (like the mutations in familial retinoblastoma and in familial polyposis of the colon).

\section{Nomenclature of MEN 2 syndromes}

At the Heidelberg meeting the organising committee made the following suggestions to achieve uniformity:

Clinical syndromes: MEN 2, MEN 2A, MEN 2B (not, for example, MEN-II, MEA, MEN-2, MEN 2a, MEN 2b, MEN 3)

Genes: MEN 2A, MEN 2B; MEN 2 for the gene for the syndrome where MEN 2A and MEN 2B are both included

Medullary thyroid carcinoma: MTC; not MCT. The two types of MTC are hereditary and non-hereditary

In that case in at least some families the MEN 2 mutation should be associated with the deletion of a sizable piece of DNA, which might easily be detected using the physical map, and the gene should almost certainly be found within the next year or so. An alternative is that the mutation that causes MEN 2 might be a single codon change leading to alteration of a single amino acid and a critical change in the conformation of the protein product. To detect a gene with that kind of mutation might require a functional assay in an appropriate cell type. The cell biology of MEN 2 is not well developed, so in this case the search might be much longer. Faced with these alternatives most laboratories are backing the search for a deletion.

Do advances of this kind in molecular genetics offer any help to clinicians? Until the gene is found molecular diagnosis cannot sort out the problem of whether an apparently isolated patient with medullary thyroid carcinoma has a hereditary disorder. In known families where two or more affected members can be studied, however, a genetic prediction based on the inheritance of DNA markers is already possible in about four fifths of cases. If only one marker is used, depending on the marker and the family members available, the accuracy of prediction is about $95-99 \%$ for children of an affected man and $90-96 \%$ for children of an affected woman..$^{910}$ (Prediction is less accurate if inheritance is from a woman because the frequency of genetic recombination between close markers and the MEN 2 gene is higher in women.) If two markers either side of the MEN 2 gene (for example, interstitial retinol binding protein and $14 \cdot 34$ ) are used together and no recombination is seen the probability of error falls to $1 \%$ or less. These figures - and the proportion of families that can be helped-will improve as more markers are defined.

As with all such genetic tests much is still to be learnt about 